\title{
EFEITO DA CORRUPÇÃO SOBRE A EFICIÊNCIA INSTITUCIONAL DOS PAÍSES
}

\author{
Loredany Consule Crespo Rodrigues * \\ Adriano Provezano Gomes ${ }^{\dagger}$ \\ Evandro Camargos Teixeira $\ddagger$
}

\begin{abstract}
Resumo
O objetivo desse estudo é analisar o efeito da corrupção sobre a eficiência das instituições. Para tal, inicialmente, calculou-se o índice de eficiência institucional por meio da análise envoltória de dados. Por meio das referidas medidas, verificou-se que os países institucionalmente eficientes são os menos corruptos e a corrupção impacta negativamente a eficiência das instituições. Sendo assim, considerando a relevância das instituições para o crescimento e desenvolvimento dos países, ressalta-se a importância da formulação de políticas públicas que combatam a corrupção, pois, dessa forma, as instituições se tornarão mais eficientes e os países economicamente mais prósperos.
\end{abstract}

Palavras-chave: corrupção, eficiência institucional, análise envoltória de dados, dois estágios.

\begin{abstract}
The purpose of this study is to analyze the effect of corruption on the efficiency of institutions. First the institutional efficiency index was calculated by data envelopment analysis. Through these measures, it was found that institutionally efficient countries are the least corrupt and corruption negatively impacts the efficiency of institutions. Therefore, considering the relevance of institutions for the growth and development of countries, the importance of formulating public policies that fight corruption is emphasized, because in this way, institutions will become more efficient and the countries economically more prosperous.
\end{abstract}

Keywords: corruption perception index, institutional efficiency, data envelopment analysis, two stages.

JEL classification: D02, D73.

DOI: http://dx.doi.org/10.11606/1980-5330/ea 167508

\footnotetext{
* Doutoranda em Economia Aplicada no Departamento de Economia Rural da Universidade Federal de Viçosa (DER-UFV). e-mail: loredanyufTeixeirav@hotmail.com

${ }^{\dagger}$ Professor Titular do Departamento de Economia da Universidade Federal de Viçosa (DEE-UFV). e-mail:apgomes@ufv.br

‡ Professor Associado I do Departamento de Economia da Universidade Federal de Viçosa (DEEUFV).e-mail: evandro.teixeira@ufv.br
} 


\section{Introdução}

O aumento significativo da corrupção em boa parte do mundo e seus diversos impactos causados à sociedade têm chamado a atenção dos cidadãos e se tornado um tema relevante entre os pesquisadores. Segundo a Transparência Internacional (2017), embora existam diversas formas de corrupção, ela sempre envolve o abuso do poder confiado para ganhos privados ${ }^{1}$. Isto é, a corrupção está associada a atos de políticos e servidores públicos que se beneficiam às custas do bem público.

Ainda de acordo com Transparência Internacional (2017), órgão que calcula o Índice de Percepção da Corrupção ${ }^{2}$ (IPC), a maioria dos países apresenta pouco ou nenhum progresso em relação à eliminação total da corrupção. Em 2017, mais de dois terços dos países avaliados apresentaram IPC inferior a 50 (média de 43), e esse desempenho não é muito diferente nos anos anteriores. É importante ressaltar que esse índice considera a percepção de especialistas e executivos em relação à corrupção no setor público de determinado país. Nesse sentido, Ortiz-Ospina \& Roser (2016) demonstram que percepção e comportamento estão correlacionados ${ }^{3}$.

Dessa forma, as informações apresentadas são preocupantes, tendo em vista que além de inúmeros prejuízos sociais, a corrupção, segundo Romer (1994), dificulta a entrada de novas empresas no mercado, inovação tecnológica e introdução de novos produtos, além de aumentar a incerteza e piorar a qualidade dos serviços públicos prestados.

Além disso, de acordo com Mauro (1995), a corrupção desestimula os investimentos, pois a exigência de subornos e propinas para aquisição da permissão necessária para implementação de projetos pode reduzir a margem de lucro dos empresários. Cabe ainda salientar que a corrupção pode afetar o crescimento econômico ao influenciar a escolha de projetos pelos governantes, privilegiando aqueles de interesse particular em detrimento aos de interesse da sociedade.

Nesse ínterim, para Tanzi \& Davoodi (1997), a corrupção impacta negativamente a eficiência institucional, haja vista que ela aumenta o investimento público, mas concomitantemente reduz sua produtividade. Assim, o combate à corrupção é fundamental para que as instituições atuem de forma cada vez mais eficiente, criando condições necessárias para o crescimento sustentado.

\footnotetext{
${ }^{1}$ Embora neste trabalho tenha sido adotada a definição da Transparência Internacional, há outras definições de corrupção, não sendo restrita ao setor público. Nesse sentido, a corrupção ainda pode ser definida como quebra de regras, normas ou padrões estabelecidos (Tanzi 1998). Adicionalmente, de acordo com o Código Penal brasileiro, a corrupção pode ser ativa em que são oferecidas ou prometidas vantagens indevidas ao funcionário público, para determiná-lo a praticar, omitir ou retardar ato de ofício (art. 333); ou passiva, que equivale a solicitar ou receber, para si ou para outrem, direta ou indiretamente, ainda que fora da função ou antes de assumi-la, mas em razão dela, vantagem indevida, ou aceitar promessa de tal vantagem (art. 317).

${ }^{2}$ Índice calculado anualmente que mede os níveis percebidos de corrupção no setor público em todo o mundo. O IPC varia de 0 a 100 e quanto maior seu valor, menor é a percepção de corrupção no país. Para obter esse índice, a Transparência Internacional reúne dados de diversas fontes que fornecem percepções de empresários e especialistas sobre o nível de corrupção no setor público (Transparência Internacional 2016).

${ }^{3}$ No Anexo A, encontra-se a figura elaborada por Ortiz-Ospina \& Roser (2016) por meio do qual é possível visualizar a relação entre percepção da corrupção, medida pelo IPC, e comportamento corrupto, mensurado pelo percentual de pessoas que participaram da pesquisa e que relataram ter pago suborno para acessar serviços públicos no último ano.
} 
Diante disso, questiona-se a respeito de um possível impacto da corrupção na eficiência das instituições. De acordo com De Vaal \& Ebben (2011), a corrupção faz parte do ambiente institucional, exercendo um efeito crucial sobre a estrutura institucional dos países. Assim, considerando a importância das instituições para o crescimento econômico e a presença da corrupção no ambiente institucional, o presente estudo tem como objetivo analisar o efeito causado pela corrupção na eficiência das instituições. Para tal, são analisados 129 países, cuja relação encontra-se no Apêndice. Inicialmente, é calculado o índice de eficiência institucional para cada um desses países, utilizando-se a análise envoltória de dados (DEA). Posteriormente, por meio de análises econométricas, verifica-se o efeito da corrupção sobre a eficiência das instituições.

O presente estudo contribui com a literatura especializada, pois embora de maneira geral admita-se que a corrupção afeta negativamente a eficiência, poucos trabalhos buscam mensurar tal impacto. Ressalta-se que além deste trabalho ser inovador ao considerar o efeito da corrupção sobre a eficiência das instituições, a pesquisa cria um índice de eficiência institucional que pode ser utilizado pelos tomadores de decisão e formuladores de políticas como medida de avaliação institucional.

Adicionalmente, os resultados obtidos podem auxiliar a formulação de políticas de combate à corrupção, direcionando e aprimorando estratégias de fiscalização de órgãos públicos, promovendo, por exemplo, instituições mais eficientes.

O trabalho está organizado em seis seções, incluindo esta introdução. A segunda seção apresenta alguns estudos relacionados aos efeitos da corrupção sobre o desempenho econômico com posterior apresentação do referencial teórico que embasa o estudo e a metodologia utilizada. A quinta seção é composta pelos resultados e discussão e, por último, na sexta seção, são apresentadas as considerações finais do trabalho.

\section{Evidências Empíricas dos Efeitos da Corrupção Sobre o Desemoenho Econômico}

Como já mencionado, a corrupção tem se tornado um problema enfrentado por inúmeros países, causando prejuízos nos mais diversos aspectos. Diante disso, estudos que busquem avaliar os efeitos causados pela corrupção são de suma importância em uma sociedade onde os atos corruptos estão cada vez mais presentes.

Lambsdorff (2003) verificou o impacto da corrupção sobre a produtividade de sessenta e nove países de diversos continentes. Para determinar a produtividade, o autor utilizou a razão entre Produto Interno Bruto (PIB) e estoque de capital, e concluiu que a redução da corrupção pode elevar significativamente a produtividade de determinado país, aumentando seu PIB. Ao decompor a corrupção em subcomponentes, o autor identificou que a qualidade burocrática, a liberdade civil e a estabilidade do governo possuem relação positiva e significativa com a produtividade, sendo a primeira de maior relevância.

O estudo realizado por Salinas Jiménez \& Salinas Jiménez (2006) analisou o efeito da corrupção nos níveis de produtividade e na taxa de crescimento de vinte e dois países da OCDE entre 1980 e 2000. Utilizando a abordagem de fronteira de produção e diferentes indicadores de corrupção, os autores 
concluíram que esta tem efeito negativo nos níveis de eficiência dos países analisados e as taxas de crescimento são maiores em países menos corruptos.

Aidt et al. (2008) identificaram como a corrupção afeta o crescimento econômico, considerando diferentes regimes de governança. Ao identificar dois regimes determinados pela qualidade das instituições políticas de duas amostras de países, uma contendo 67 e outra 71 países de cinco continentes, concluíram que a relação entre corrupção e crescimento econômico não é linear. Enquanto nos regimes cujas instituições políticas são de alta qualidade a corrupção tem impacto negativo sobre o crescimento, nos regimes com instituições políticas de baixa qualidade, a corrupção não afeta o crescimento.

De Vaal \& Ebben (2011) desenvolveram um modelo que demonstra a importância das instituições para determinar a relação entre corrupção e crescimento econômico. Por meio de um modelo de dois níveis, os autores enfatizaram o poder decisivo das instituições nessa relação, revelando a possibilidade de a corrupção favorecer o crescimento econômico na presença de instituições não desenvolvidas.

Na literatura nacional, os estudos realizados avaliam o efeito da corrupção sobre o crescimento e desenvolvimento econômicos sem considerar o impacto causado na eficiência das instituições.

Nesse sentido, Hayashi (2012) utilizou dois indicadores mundiais, o Índice de Percepção de Corrupção (IPC) e o Índice de Controle da Corrupção (ICC), para verificar o impacto da corrupção sobre o desenvolvimento econômico. Os resultados revelam que a relação entre as variáveis é negativa e o prejuízo é causado sobre todos os aspectos do desenvolvimento: econômico, social, político e cultural. Adicionalmente, o autor concluiu que a corrupção tem efeito sobre os direitos humanos, comprometendo a consolidação da democracia.

Por meio de uma pesquisa bibliográfica, Gottschild (2016) buscou delinear as vertentes predominantes nos estudos realizados que analisam os efeitos da corrupção sobre o processo de desenvolvimento econômico, identificando os mecanismos de interação entre essas variáveis. O autor concluiu que, embora ainda não haja consenso, a maior parte dos estudos encontra relação negativa entre corrupção e desenvolvimento. Os resultados ainda revelam que a corrupção está correlacionada à desigualdade de renda, à promoção de firmas ineficientes e à redução do gasto social, do crescimento econômico, da eficiência dos contratos e dos investimentos particulares e externos.

Diante do exposto, nota-se que as consequências da corrupção são amplas, e grande parte delas está relacionada com variáveis institucionais. Sendo assim, pode-se dizer que uma das formas pelas quais a corrupção prejudica o desempenho econômico é por meio de seu impacto nas instituições.

\section{Corrupção no Ambiente Institucional: A Teoria do Principal-Agente}

A corrupção tem trazido os mais diversos efeitos sobre a sociedade, sendo um destes o que afeta as instituições. Conforme North (2006), as instituições são as regras sociais criadas pelos indivíduos para que possam interagir e viver em sociedade. Porém, não basta que tais regras sejam bem definidas se não forem corretamente aplicadas. Sendo assim, é de suma importância a existência de instituições que garantam a aplicação dessas regras, isto é, instituições eficientes. 
Além das regras que regem a sociedade, é importante enfatizar que os serviços públicos são ofertados para os cidadãos por meio das instituições, que são compostas por funcionários cujo dever é atender aos interesses públicos. Nesse sentido, segundo Acemoglu \& Robinson (2012), a provisão de serviços públicos, proporcionando condições igualitárias para os indivíduos, é uma das funções do Estado.

De acordo com Aidt (2003), a partir do momento que o governo delega atividades como a implementação de políticas específicas e o controle e execução de regulações aos burocratas, estes passam a ter um poder que pode ser utilizado para atividades corruptas. Desse modo, para que as instituições sejam eficientes, é necessário que os burocratas atuem de forma honesta.

É importante ressaltar que, conforme Araújo \& Sanchez (2005), os burocratas possuem o poder administrativo, necessário para realização de seu trabalho, caracterizado por ser vinculado às leis e discricionário. Eles possuem também o poder burocrático, resultante da competência técnica, do conhecimento específico e da posse de informações que o principal não possui. Nesse sentido, os autores definem que o poder administrativo é extrínseco aos burocratas; já o poder burocrático é intrínseco.

Assim, principalmente por meio do poder intrínseco, os burocratas podem se corromper em busca de seus próprios interesses. Nesse caso, os serviços prestados pelas instituições serão prejudicados, a produtividade será reduzida e as instituições deixarão de ser eficientes. Vale ressaltar que se trata de um processo com elevada complexidade, haja vista a rede de relacionamentos existente no ambiente institucional e os inúmeros fatores que influenciam essa relação (assimetria de informação, moral hazard, seleção adversa, conflito de interesses, monitoramento, custos e incentivos). Logo, o comportamento do agente, resultante dessa relação dinâmica e complexa, afeta a eficiência das instituições.

Segundo Svensson (2005), diversos estudos indicam que a corrupção dos agentes responsáveis pela aplicação das regras e leis é a maior causa da ineficiência institucional. Conforme Bueno (2009), a corrupção implica atuação com baixo nível de eficiência das instituições, favorecendo interesses particulares em detrimento dos interesses sociais.

Nesse sentido, pode-se dizer que a corrupção afeta a eficiência institucional por meio dos atos corruptos praticados por seus representantes (os burocratas). De acordo com Bueno (2009), a corrupção reduz a eficiência econômica e o bem-estar dos cidadãos ao reduzir a capacidade governamental em corrigir falhas de mercado por meio de regulamentações e controle; ao induzir a alocação de recursos para atividades não produtivas (rent-seeking); ao reduzir a renda potencial dos mais pobres, elevando o grau de pobreza acima dos níveis que poderia estar; e ao reduzir a legitimidade da economia de mercado e da própria democracia.

Cabe ainda enfatizar que a corrupção passa a fazer parte das instituições a partir do momento em que seus funcionários priorizam interesses particulares em detrimento do interesse público. Ou seja, diante da racionalidade limitada resultante da assimetria de informações presente no ambiente institucional, surge o comportamento oportunista em que os agentes utilizam as informações que possuem para atender seus próprios interesses (Araújo \& Sanchez 2005). Assim, o problema da corrupção em instituições públicas 
pode ser modelado como o problema do "Principal-Agente"4 (Bueno 2009).

De acordo com Araújo \& Sanchez (2005), essa teoria é uma ferramenta relevante para compreender as relações contratuais delegativas, em que incentivos e controles são essenciais, caso característico das burocracias públicas. São considerados dois atores, o principal e o agente, sendo que o primeiro é representado pelo indivíduo que, para alcançar seus objetivos, delega algumas responsabilidades a outro, o agente. Dessa forma, a partir do momento em que o governo, representante do povo, "cria" instituições para atender às demandas da sociedade, ele se torna o principal e os burocratas (funcionários das instituições), o agente.

Conforme Carraro \& Hillbrecht (2003), o problema surge porque o agente possui informações que são desconhecidas ou inobservadas pelo principal, podendo agir para atender seus próprios interesses. Nesse caso, os objetivos do governo, isto é, os interesses da sociedade, não serão atendidos. Logo, é fundamental que os agentes sejam pessoas íntegras para que o serviço prestado seja de qualidade.

Em outras palavras, uma das premissas da teoria do "Principal-Agente" é que as informações são assimétricas e, se os detentores dessas informações (agente) se corromperem, essa relação se torna ineficiente. Ou seja, a corrupção interfere na eficiência institucional, impedindo que o objetivo do governo de maximizar o bem-estar social seja alcançado.

Segundo Schillemans (2013), a partir do momento em que os agentes buscam maximizar sua utilidade, priorizando os próprios interesses em detrimento do interesse público, eles se corrompem, prejudicando as instituições. Para Carraro \& Hillbrecht (2003), o comportamento do agente é fundamental para a eficiência e o decoro na administração pública.

Nesse sentido, tornam-se de suma importância estratégias para evitar o referido comportamento no ambiente institucional. O objetivo é convergir ao máximo os interesses do agente e do principal. Dada a propensão ao oportunismo do agente, há dois problemas que devem ser considerados nessa relação: seleção adversa (adverse selection) e risco moral (moral hazard) (Araújo \& Sanchez 2005). O primeiro refere-se às características do agente que não são conhecidas pelo principal e só podem ser observadas por meio de sinalizações emitidas pelo próprio. O segundo corresponde à não observância das atitudes do agente após o contrato ser firmado entre as partes.

Mais uma vez, destaca-se o comportamento do agente como determinante da corrupção no ambiente institucional. Importante ressaltar que a relação principal-agente é ampla. Em outras palavras, trata-se de uma rede de relações hierárquicas em que um mesmo funcionário pode exercer o papel de agente e principal em relações distintas. Nesse sentido, Araújo \& Sanchez (2005) destacam algumas características que determinam o sucesso dessa relação, conforme segue: na elaboração do contrato, devem ser previstas as inúmeras possibilidades de comportamento do agente; devem ser delineados incentivos que visem a convergência entre os interesses do agente e do principal; e um sistema de seleção e de monitoramento e controle confiável deve ser estabelecido quando não for possível a observância contínua do agente pelo titular e no caso desse não saber julgar aquele. Como as instituições são responsáveis

\footnotetext{
${ }^{4}$ Para Melo (1996), as transações sociais no contexto de relações hierárquicas, em organizações e burocracias, nas relações de mercado e no quadro de instituições políticas podem ser modeladas pela teoria do Principal-Agente.
} 
por essas relações, os autores denotam a importância de arranjos institucionais que limitem e constranjam o comportamento oportunista dos agentes.

Cabe ainda destacar que as instituições têm papel determinante no crescimento e desenvolvimento de um país, sendo de suma importância que sejam de qualidade. De acordo com Acemoglu \& Robinson (2012), as instituições promovem o desenvolvimento de uma nação à medida que criam incentivos e influenciam o comportamento dos cidadãos. Nesse contexto, considerando os diversos efeitos que a corrupção tem trazido à sociedade, o presente estudo, como já salientado, objetiva mensurar o efeito da corrupção na eficiência das instituições.

\section{Metodologia}

Nesta seção, são apresentados os procedimentos metodológicos utilizados para alcançar os objetivos propostos. Inicialmente, para estimar as medidas de eficiência institucional dos países, é utilizado um método não paramétrico: a análise envoltória de dados (DEA). Posteriormente, para verificar o efeito da corrupção sobre as medidas de eficiência, optou-se pela utilização do procedimento de bootstrap proposto por Simar \& Wilson (2007), que permite a obtenção de estimativas robustas nos casos de análises de determinantes de escores de eficiência. Ambos os métodos, assim como o procedimento proposto e a fonte de dados utilizada nesta pesquisa, são apresentados nas subseções a seguir.

\subsection{Análise envoltória de dados}

A análise envoltória consiste em uma abordagem não paramétrica que analisa a eficiência relativa de unidades produtivas, denominadas DMUs (decision making units), capazes de transformar múltiplos insumos em múltiplos produtos Cooper et al. (2007). Há dois modelos possíveis a serem utilizados nessa abordagem: o modelo elaborado por Charnes et al. (1978), que considera retornos constantes à escala (CCR); e o modelo elaborado por Banker et al. (1984), que considera retornos variáveis à escala (BCC).

Por meio do referido método, é criada uma fronteira eficiente composta pelos países institucionalmente eficientes. É importante ressaltar que a medida de eficiência leva em consideração a relação entre insumos e produtos, ou seja, uma unidade é considerada eficiente caso produza relativamente mais, mantendo fixa a quantidade de insumos (orientação produto); ou utilize menos insumos para dada quantidade de produto (orientação insumo).

Nesse contexto, são construídas duas matrizes com coeficientes não negativos e com pelo menos um coeficiente positivo em cada linha e cada coluna: uma matriz $X$ de insumos $(k \times n)$ e uma matriz $Y$ de produtos $(m \times n)$, em que $k$ representa os insumos, $m$ os produtos e $n$ as DMUs. Nesta pesquisa, assumese que a qualidade institucional dos países pode ser impactada pela forma de condução do governo. Nesse sentido, dado que cada país possui um único governo, utiliza-se o modelo de insumo unitário, em que o vetor correspondente aos pesos dos insumos é ajustado igual a 1 para todos os países (v $x_{i}=1$ ). Sendo assim, obtém-se a eficiência institucional (EI) de cada país conforme segue: 


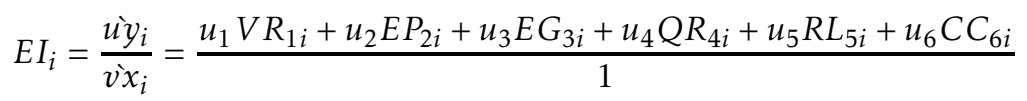

Em que $u$ representa o vetor de pesos nos produtos, $V R$ refere-se à voz $\mathrm{e}$ responsabilidade do país, que denota a participação dos cidadãos na escolha do governo, assim como liberdades de expressão e associação e mídia livre do país; $E P$ refere-se à estabilidade política, que captura a probabilidade de instabilidade política e violência politicamente motivada, inclusive atos terroristas; EG refere-se à eficácia do governo, capturando a percepção em relação à qualidade dos serviços públicos e à credibilidade do governo em relação ao compromisso com as políticas formuladas e implementadas; $Q R$ refere-se à qualidade regulatória, relacionada com a capacidade governamental em formular e implementar políticas e regulamentos sólidos, beneficiando o desenvolvimento do setor privado; $R L$ refere-se às regras da lei que denota a confiança e respeito dos agentes em relação às regras da sociedade, assim como a qualidade dos direitos de propriedade e da execução dos contratos; e CC refere-se ao controle da corrupção, que identifica até que ponto o poder público é exercido para ganhos "privados". Essas variáveis foram selecionadas de acordo com estudo realizado por Votápková \& Zác (2013) e referem-se aos indicadores mundiais de governança, que são disponibilizados pelo Banco Mundial para mais de 200 países e territórios desde 1996 (Worldwide Governance Indicators - WGI 2017).

Cabe ainda ressaltar que a ponderação das variáveis é uma das dificuldades encontradas quando objetiva-se mensurar a eficiência de unidades produtivas com múltiplos insumos e produtos. Nesse sentido, a análise envoltória de dados permite a solução dessa dificuldade por meio de um programa matemático em que um conjunto de pesos é selecionado para cada unidade, de tal forma que sua eficiência relativa seja maximizada.

Nesta pesquisa, como já mencionado, utiliza-se o modelo com orientação produto, dado que o país institucionalmente eficiente é aquele que maximiza, simultaneamente, os indicadores mundiais de governança e assume-se retornos constantes à escala. Sendo assim, conforme Coelli et al. (1998), as medidas de eficiência são obtidas por meio do problema de maximização a seguir:

$$
\begin{aligned}
& \operatorname{Max}_{\phi, \lambda} \phi, \\
& \text { sujeito } a: \\
& -\phi y_{i}+Y \lambda \geq 0, \\
& x_{i}-X \lambda \geq 0, \\
& \lambda \geq 0,
\end{aligned}
$$

Em que $1 \leq \phi<\infty$ e $\phi-1$ é o aumento proporcional nos produtos que poderiam ser obtidos pelo $i$-ésimo país, mantendo-se constante a utilização de insumos. Dessa forma, a medida de eficiência técnica é dada por $1 / \phi$, que varia de 0 a 1 e o país que obtém valor igual a 1 é considerado institucionalmente eficiente. O parâmetro $\lambda$ é um vetor $(n \times 1)$, cujos valores são calculados de forma a obter a solução ótima. Caso o país seja institucionalmente eficiente, todos os valores de $\lambda$ serão 0 . Caso contrário, os valores de $\lambda$ serão os pesos utilizados na combinação linear de outros países eficientes que influenciam a projeção do país ineficiente sobre a fronteira calculada. 
Portanto, utilizando-se o modelo de insumo unitário com orientação produto, é possível calcular o índice de eficiência institucional de cada país analisado, em que os considerados eficientes são aqueles que maximizam, simultaneamente, as seis dimensões dos indicadores mundiais de governança. $\mathrm{Ou}$ seja, por meio desse método, é possível avaliar diversos indicadores institucionais simultaneamente e não de forma isolada, como a grande maioria dos estudos faz.

\subsection{Eficiência institucional e corrupção: o modelo analítico}

Diversos estudos têm buscado identificar os inúmeros efeitos causados pela corrupção, porém, não há consenso de que esses sejam sempre negativos. Alguns autores (Leff 1964, Lui 1985, Méon \& Weill 2010, De Vaal \& Ebben 2011) acreditam que o arcabouço institucional é fator determinante, sendo possível que a corrupção tenha efeito positivo no desempenho econômico dos países, cujas instituições são frágeis ${ }^{5}$.

No entanto, embora os estudos levem em consideração o ambiente institucional na avaliação dos impactos causados pela corrupção no desempenho econômico dos países, suas análises não avaliam o efeito da corrupção sobre a eficiência institucional, considerando o ambiente institucional como dado, ou seja, como uma variável exógena em seus modelos.

Contudo, como apresentado na seção anterior, a corrupção pode afetar significativamente as atividades institucionais. Diante disso, para atender ao objetivo desta pesquisa, isto é, para verificar o efeito da corrupção sobre a eficiência das instituições, utiliza-se o procedimento bootstrap de (Simar \& Wilson 1998, 2007).

Cabe destacar que a maior parte dos estudos que analisa os determinantes de medidas de eficiência utiliza o modelo Tobit, dado que os escores de eficiência restringem-se ao intervalo [0,1]. Porém, a utilização do referido modelo nesses casos tem sido questionada. O estudo realizado por Simar \& Wilson (2007) demonstra que o Tobit tradicional falha, apresentando resultados inconsistentes, quando trata-se de modelos que analisam os determinantes dos escores de eficiência. Os autores ainda apresentam o procedimento adequado para obter resultados robustos e consistentes nesses casos, e esse é o procedimento adotado nesta pesquisa.

Formalmente, o modelo estimado pode ser apresentado pela equação a seguir:

$$
e i_{i}=\beta_{0}+\beta_{1} i p c_{1 i}+\beta_{2} i l e_{2 i}+\beta_{3} i l p_{3 i}+\beta_{4} e l f_{4 i}+\beta_{5} c t_{5 i}+\beta_{6} d i p c_{6 i}+\varepsilon_{i}
$$

Em que, $i$ representa o país; $\beta$ são os parâmetros estimados e; $\varepsilon$ os erros aleatórios.

A descrição e a relação esperada das variáveis utilizadas são apresentadas na Tabela 1. Ressalta-se que estudos que buscam identificar os determinantes da eficiência institucional são escassos. No entanto, algumas pesquisas

\footnotetext{
${ }^{5}$ Para exemplificar como esse efeito positivo pode ocorrer, Lui (1985) apresenta um modelo de fila em que os indivíduos que decidem pagar suborno aos burocratas terão seu tempo de espera reduzido. Por meio desse modelo, o autor conclui que é possível que o suborno/corrupção sirva como "lubrificante" em uma economia lenta e com instituições ineficientes, uma vez que o mecanismo de propina classifica os clientes de forma otimizada, podendo, inclusive, elevar a velocidade do serviço prestado.
} 
identificaram os determinantes da qualidade institucional (Borner et al. 2004, Kandil 2009, Alonso \& Garcimartín 2013, Javed 2013).

Tendo em vista que o índice de eficiência institucional calculado na presente pesquisa considera variáveis qualitativas, assume-se que uma instituição eficiente é, consequentemente, uma instituição de qualidade. Sendo assim, a partir da análise desses estudos e baseado no referencial teórico apresentado, algumas variáveis foram selecionadas a fim de verificar o quanto influenciam a eficiência institucional.

Tabela 1: Descrição das variáveis utilizadas no modelo estimado para determinar o impacto da corrupção sobre a eficiência institucional dos países

\begin{tabular}{|c|c|c|}
\hline Variáveis & Descrição & $\begin{array}{c}\text { Sinais } \\
\text { esperados }\end{array}$ \\
\hline ei & $\begin{array}{l}\text { Medida de eficiência institucional, obtida por } \\
\text { meio da técnica DEA. O índice varia de } 0 \text { a } 1 \text {, e } \\
\text { quanto maior, mais eficientes são as instituições do } \\
\text { país. Trata-se da variável dependente do modelo. }\end{array}$ & - \\
\hline ipc & $\begin{array}{l}\text { Índice de Percepção da Corrupção. Trata das per- } \\
\text { cepções de corrupção no setor público. O índice } \\
\text { varia de } 0 \text { a } 100 \text {, em que } 0 \text { é altamente corrupto e } \\
100 \text { é minimamente corrupto. }\end{array}$ & Positivo \\
\hline ile & $\begin{array}{l}\text { Índice de liberdade econômica. Trata-se do índice } \\
\text { que classifica os países de acordo com " } 12 \text { liber- } \\
\text { dades", dos direitos de propriedade à liberdade fi- } \\
\text { nanceira. Varia de } 0 \text { a } 100 \text { e quanto maior, mais } \\
\text { "livre" o país. }\end{array}$ & Positivo \\
\hline ilp & $\begin{array}{l}\text { Índice de liberdade política e corresponde ao Free- } \\
\text { dom House Index, que representa o valor médio dos } \\
\text { níveis de liberdade civil e direitos políticos do país. } \\
\text { O índice varia de } 1 \text { a } 7 \text { e quanto maior, menos "li- } \\
\text { vre" o país. }\end{array}$ & Negativo \\
\hline elf & $\begin{array}{l}\text { Fragmentação etnolinguística. Mede a probabili- } \\
\text { dade de que dois indivíduos sorteados aleatoria- } \\
\text { mente na população do mesmo país pertençam a } \\
\text { grupos étnicos ou linguísticos distintos. }\end{array}$ & Negativo \\
\hline $\mathrm{ct}$ & $\begin{array}{l}\text { Carga tributária. Refere-se a transferências com- } \\
\text { pulsórias para o governo central para fins públicos. } \\
\text { Multas, penalidades e a maioria das contribuições } \\
\text { para a previdência social estão excluídas. Reem- } \\
\text { bolsos e correções de receita fiscal incorretamente } \\
\text { coletada são tratados como receita negativa. }\end{array}$ & Positivo \\
\hline $\operatorname{dipc}$ & $\begin{array}{l}\text { Dummy de inclinação que captura o efeito de inte- } \\
\text { ração entre o nível de desenvolvimento ( } \mathrm{d}=1 \text { para } \\
\text { desenvolvido e } \mathrm{d}=0 \text { para em desenvolvimento) do } \\
\text { país e o índice de percepção da corrupção. }\end{array}$ & Positivo \\
\hline
\end{tabular}

Fonte: Elaboração própria, conforme informações da Transparência Internacional (2017); Freedom House (2016), Índice de Liberdade Econômica - The Heritage Foundation (2016), Easterly \& Levine (1997), ? e International Monetary Fund - IMF (2017).

A corrupção é representada pelo IPC. Ainda que esse índice represente a percepção de especialistas e executivos em relação à corrupção do setor pú- 
blico de determinado país, alguns estudos, como o de Olken (2009), demonstram que informações sobre o comportamento corrupto estão contidas na percepção da corrupção. Adicionalmente, segundo Ortiz-Ospina \& Roser (2016), países onde os indivíduos relatam ter de pagar subornos com frequência são aqueles que tendem a apresentar maior percepção de corrupção (ver Anexo Apêndice A). Considera-se ainda que a medida do grau de corrupção por meio de pesquisas de percepção tem sido muito utilizada, especialmente quando há comparação entre países (Ayub 2015). Diante do exposto, optou-se por essa variável como proxy da corrupção. Ainda assim, é importante ressaltar que os resultados devem ser analisados com cautela, pois o IPC não corresponde a uma medida precisa do nível de corrupção.

De acordo com Svensson (2005); Tanzi (1998) e Mauro (1995), a corrupção pode impactar a eficiência das instituições por meio de fraudes em licitações, em que a empresa ganhadora pode não ser a que apresentou efetivamente as melhores condições de prestação do serviço; por meio de desvios do orçamento público para benefícios particulares e/ou por meio de superfaturamento. Em todos os casos, a produtividade do investimento público é reduzida, ou seja, o investimento se torna ineficiente.

Segundo Méon \& Weill (2005), a corrupção prejudica a alocação dos recursos, tornando sua utilização menos intensiva, além de elevar a instabilidade política. Consequentemente, o impacto da corrupção sobre a eficiência das instituições é negativo.

Cabe ainda ressaltar que conforme a Teoria do Principal-Agente, a partir do momento que o agente (funcionários das instituições) prioriza seus próprios interesses em detrimento ao interesse público, a corrupção passa a fazer parte do ambiente institucional, reduzindo sua produtividade e, consequentemente, sua eficiência. Logo, dado que quanto maior o IPC, menor a percepção de corrupção no país, espera-se relação positiva entre essa variável e a eficiência institucional.

O índice de liberdade econômica (ile) é inserido no modelo a fim de verificar o quanto ele afeta as instituições. Conforme Carraro \& Hillbrecht (2003), em países onde não há liberdade econômica, o governo possui poder discricionário na alocação dos recursos públicos, que passa a ser realizada de forma política ou burocrática, e isso pode interferir na eficiência das instituições. De acordo com Acemoglu \& Robinson (2012), direitos de propriedade bem estabelecidos e mobilidade de capital (liberdade financeira) são características de instituições de qualidade que, por sua vez, são fundamentais para o desenvolvimento econômico. Em outras palavras, liberdade econômica e eficiência institucional estão associadas.

Adicionalmente, Adkins et al. (2002), Méon \& Weill (2005), Dang (2009), Kandil (2009) e Javed (2013) relacionam positivamente esse índice com a qualidade institucional. Sendo assim, espera-se que quanto maior o índice de liberdade econômica, mais eficientes as instituições de determinado país.

Para Borner et al. (2004), a liberdade civil contribui para um melhor ambiente institucional à medida que restringe o comportamento do governo, $\mathrm{e}$ a democracia é fator determinante para a existência de instituições de qualidade. Levando-se em consideração que o governo tem a função de supervisionar a produção de serviços públicos, o controle dos cidadãos pode influenciar a eficiência das instituições (Aidt et al. 2008). Desse modo, a liberdade civil e os direitos políticos, representados pela variável índice de liberdade política (ilp), são incluídos como determinantes da eficiência institucional e espera- 
se relação negativa entre elas, ou seja, quanto maior o índice (menos livre o país), menos eficientes são suas instituições. Outros autores (Dang 2009, Sachsida 2011) utilizam essa mesma variável como medida de instituições de qualidade.

A fragmentação etnolinguística (elf) foi selecionada a fim de verificar se a heterogeneidade da população interfere de alguma forma na eficiência das instituições. Segundo Alonso \& Garcimartín (2013), maior diversidade pode gerar conflitos e reduzir a cooperação entre diferentes grupos. Os autores destacam que essa variável está relacionada a características históricas dos países e são tradicionalmente consideradas, podendo afetar a qualidade das instituições por meio do seu impacto na distribuição dos recursos ${ }^{6}$, por exemplo.

Para Méon \& Weill (2005), é possível que essa variável esteja associada a maior turbulência política em um país. Assim, segundo Alesina et al. (2003), países onde a sociedade é segmentada têm maior dificuldade em redistribuir os recursos de forma consensual, afetando a eficiência das instituições. Ademais, os conflitos nesses países são mais intensos, dificultando a atuação democrática dos governos. Nesse sentido, para Easterly et al. (2006), a qualidade institucional é determinada, em parte, pela coesão social ${ }^{7}$. Os autores argumentam que nos países com maior coesão social, instituições eficientes são mais facilmente encontradas. Desse modo, espera-se relação negativa entre fragmentação etnolinguística e eficiência institucional.

Com relação à carga tributária, espera-se que seu efeito sobre a eficiência seja positivo, tendo em vista que o sistema tributário é uma variável crucial para a eficiência institucional, pois fornece os recursos necessários para construção de instituições eficientes de forma transparente, não sendo necessária coleta de recursos de outras fontes (Alonso \& Garcimartín 2013). Adicionalmente, conforme Borner et al. (2004), somente um Estado com recursos suficientes é capaz de proteger os direitos de propriedade contra a demanda de grupos específicos. Alonso \& Garcimartín (2013) ainda destacam que um sistema tributário sólido consolida um contrato social com maior transparência e accountability, resultando em instituições de maior qualidade.

A dummy de interação (dipc) foi incluída no modelo para capturar o efeito de interação entre o nível de desenvolvimento e o índice de percepção de corrupção sobre a eficiência institucional. Segundo Alonso \& Garcimartín (2013), o nível de desenvolvimento nacional influencia a eficiência das instituições por meio da oferta e demanda, pois ao mesmo tempo em que disponibiliza recursos para a construção de "boas" instituições, gera demanda por instituições de qualidade ou eficientes. Sendo assim, por meio dessa variável, é possível verificar se o impacto da corrupção sobre a eficiência institucional é distindo, considerando se o país é classificado como desenvolvido ou em desenvolvimento.

\subsection{Procedimento proposto e fonte de dados}

O presente estudo é realizado em duas etapas. Inicialmente, por meio da DEA e utilizando os indicadores mundiais de governança (WGI), calculam-se as

\footnotetext{
${ }^{6} \mathrm{~A}$ homogeneidade linguística pode ser um indicador da forma pela qual os diferentes grupos de determinado país desenvolveram uma identidade comum ao longo das décadas ou séculos, formando a identidade nacional. Na ausência dessa identidade, é possível que grupos étnicos sejam politicamente mobilizados (Easterly et al. 2006).

${ }^{7}$ Uma das proxies utilizadas para medir a coesão social é a fragmentação etnolinguística.
} 
medidas de eficiência institucional dos países. Após a obtenção dessas medidas, estima-se um modelo econométrico (modelo 5) para verificar o impacto da corrupção sobre a eficiência das instituições ${ }^{8}$.

A amostra é composta por 129 países selecionados de acordo com a disponibilidade de dados e cuja relação encontra-se no Apêndice. Os dados utilizados foram obtidos na base da Transparência Internacional, do Worldwide Governance Indicators - World Bank, do Heritage Foundation, do Freedom House, do Programa das Nações Unidas para o Desenvolvimento (Programa das Nações Unidas - PNUD 2018) e do Banco Mundial, todos disponíveis nos sites oficiais das respectivas organizações, e são referentes ao ano de 2016, pois trata-se do ano mais recente com dados disponíveis no período em que a pesquisa foi realizada.

\section{Resultados e Discussões}

Esta seção é composta por dois tópicos. Inicialmente, são apresentadas as medidas de eficiência das instituições obtidas pelos países analisados. Posteriormente, por meio da análise econométrica, é verificado o efeito da corrupção sobre a eficiência das instituições.

\subsection{Eficiência institucional}

Os países institucionalmente eficientes são os que maximizam, simultaneamente, seus indicadores mundiais de governança. Dessa forma, aqueles que obtiveram os melhores indicadores possuem instituições relativamente eficientes.

Entre os 129 países analisados, aproximadamente 34\% pertencem ao continente africano, $23 \%$ são países asiáticos, $19 \%$ europeus, $11 \%$ norte-americanos, $10 \%$ latino-americanos e 3\% pertencem à Oceania. Dinamarca, Finlândia, Nova Zelândia, Noruega, Países Baixos, Singapura, Suécia e Suíça obtiveram medida máxima de eficiência e foram considerados institucionalmente eficientes. Como pode-se observar na Tabela 2, a maior parte desses países (75\%) situa-se no continente europeu.

Tabela 2: Estatísticas descritivas das medidas de eficiência por continente

\begin{tabular}{l|c|c|c|c|c|c}
\hline \multirow{2}{*}{ Continente } & \multirow{2}{*}{ Média } & \multirow{2}{*}{ Máximo } & \multirow{2}{*}{ Mínimo } & \multicolumn{2}{|c|}{ Eficientes } & Total de \\
\cline { 5 - 6 } & & & & Número & $\%$ & países \\
\hline África & 0,440 & 0,906 & 0,108 & 0 & 0 & 44 \\
América do Norte & 0,641 & 0,979 & 0,266 & 0 & 0 & 14 \\
América Latina & 0,609 & 0,913 & 0,182 & 0 & 0 & 13 \\
Ásia & 0,665 & 1 & 0,220 & 1 & 3,33 & 30 \\
Europa & 0,886 & 1 & 0,610 & 6 & 25 & 24 \\
Oceania & 0,788 & 1 & 0,527 & 1 & 25 & 4 \\
\hline Total & 0,625 & 1 & 0,108 & 8 & 6,20 & 129 \\
\hline
\end{tabular}

Fonte: Resultados da pesquisa.

\footnotetext{
${ }^{8}$ Para o cálculo das medidas de eficiência, foi utilizado o software Deap, versão 2.1. Os demais procedimentos metodológicos foram realizados no software Stata 12.
} 
Constata-se ainda que dos quatro países que obtiveram índices de eficiência inferiores a 0,2 (África Central, 0,187; Chade, 0,123; República Democrática do Congo, 0,108 e Venezuela, 0,182), três pertencem ao continente africano. Tais resultados podem ser justificados pela existência de conflitos e guerras civis nesse continente, que causam instabilidade política, uma das variáveis utilizada no cálculo do índice de eficiência institucional.

Comparando-se as médias de eficiência das instituições por continente, é possível verificar que as medidas obtidas pelos continentes africano $(0,440)$ e latino-americano $(0,609)$ foram inferiores a média da amostra $(0,625)$, revelando o quanto esses países precisam evoluir em relação à qualidade de suas instituições, demandando políticas e estratégias que priorizem a eficiência institucional. Destaca-se mais uma vez a situação do continente africano, cuja média foi consideravelmente inferior a da amostra.

Nesse sentido, é válido salientar que as instituições têm papel fundamental para o desenvolvimento de qualquer país. Segundo North (2006), Furlanetto (2008) e Alonso \& Garcimartín (2013), instituições eficientes promovem um ambiente com condições necessárias e favoráveis para o desenvolvimento econômico.

Observando-se os valores obtidos pelo continente europeu (Tabela 2), podese identificar uma potencial correlação entre instituições eficientes e desenvolvimento econômico, dado que os países pertencentes a esse continente são, em sua maioria, classificados como desenvolvidos, e seis dos oito países institucionalmente eficientes estão na Europa. Tal relação também pode ser verificada por meio da Figura $1^{9}$, em que os países que obtiveram maiores medidas de eficiência (representados pela cor roxa no mapa) são classificados como desenvolvidos ${ }^{10}$.

Logo, diante da importância das instituições para o crescimento e desenvolvimento econômicos de uma nação, identificar os fatores que influenciam essa eficiência torna-se importante para o direcionamento de políticas, que visem melhorar a qualidade institucional dos países e, como resultado, sua performance econômica.

\subsection{Efeito da corrupção na eficiência das instituições}

A corrupção tem sido um grande problema enfrentado pela sociedade mundial. De acordo com Transparência Internacional (2016), a pontuação média global do IPC indica a existência de corrupção endêmica no setor público. Para De Vaal \& Ebben (2011), a corrupção afeta significativamente o ambiente institucional do país, pois a partir do momento em que passa a fazer parte do mesmo, ela influencia a alocação de recursos e as decisões burocráticas, podendo elevar os custos de transação.

A partir da Figura 2, é possível verificar que existe correlação positiva entre o índice de percepção de corrupção (IPC) e nível de eficiência institucional (EI). É importante lembrar que quanto maior o IPC, menos corrupto o país ${ }^{11}$. Logo, verifica-se que a relação entre corrupção e eficiência institucio-

\footnotetext{
${ }^{9}$ Os países foram distribuídos em três intervalos iguais, cuja sequência vai dos menos para os mais eficientes, representados pelos tons mais claros até os mais escuros, respectivamente. Os países que não foram analisados estão em branco.

${ }^{10} \mathrm{~A}$ relação dos países pertencentes a cada categoria do mapa está apresentada no Apêndice.

${ }^{11}$ Como já relatado, utiliza-se o índice de percepção de corrupção (IPC) como proxy da corrupção e, dessa forma, ainda que exista correlação entre percepção e comportamento corrupto,
} 
Figura 1: Distribuição geográfica dos países de acordo com intervalos de medidas de eficiência institucional

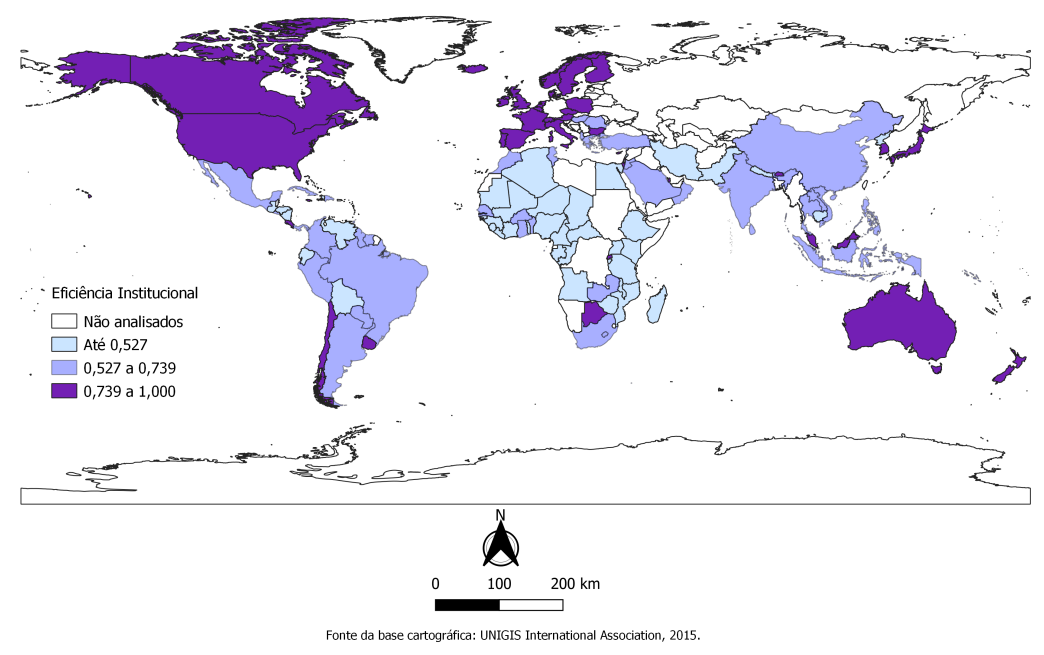

Fonte: Resultados da pesquisa.

nal é negativa, ou seja, quanto menos corrupto o país, mais eficientes são suas instituições.

Nota-se que dos oito países institucionalmente eficientes, sete obtiveram os maiores IPC, ou seja, são os países menos corruptos da amostra. Embora haja relação negativa entre corrupção e eficiência institucional, não se sabe o quanto a corrupção afeta essa eficiência. Dessa forma, a presente pesquisa busca mensurar tal relação, estimando uma regressão por meio do procedimento bootstrap de Simar \& Wilson (2007). Os resultados são apresentados na Tabela 3.

A corrupção, representada pelo índice de percepção de corrupção, apresentou significância estatística e positiva, conforme o esperado. Ou seja, quanto menos corrupto o país, mais eficientes suas instituições. Esses resultados vão ao encontro da Teoria do Principal-Agente, em que a corrupção torna as instituições menos eficientes ao interferir na atividade dos burocratas.

Para Javed (2013), a corrupção impede que as instituições alcancem eficiência produtiva e alocativa, pois facilita atividades expropriatórias. De acordo com Méon \& Weill (2005), a corrupção reduz a eficiência institucional ao atuar como um imposto sobre as atividades produtivas, reduzindo sua produção e incentivando o acúmulo de recursos menos produtivos. Sendo assim, a corrupção pode ser um dos fatores que limitam o crescimento dos países, por meio de seu efeito sobre as instituições. Em outras palavras, a corrupção interfere na alocação de recursos, podendo prejudicar a prestação de serviços para a sociedade e, consequentemente, a qualidade de vida da população.

$\mathrm{O}$ índice de liberdade econômica, como descrito na Tabela 1, varia de 0 a 100 e, quanto maior esse valor, mais "livre" é o país. Nesse contexto, o

os resultados devem ser analisados com parcimônia. Sendo assim, o termo "país menos (mais) corrupto" significa que a percepção de corrupção no referido país é menor (maior). 
Figura 2: Diagrama de dispersão entre eficiência institucional e índice de percepção da corrupção

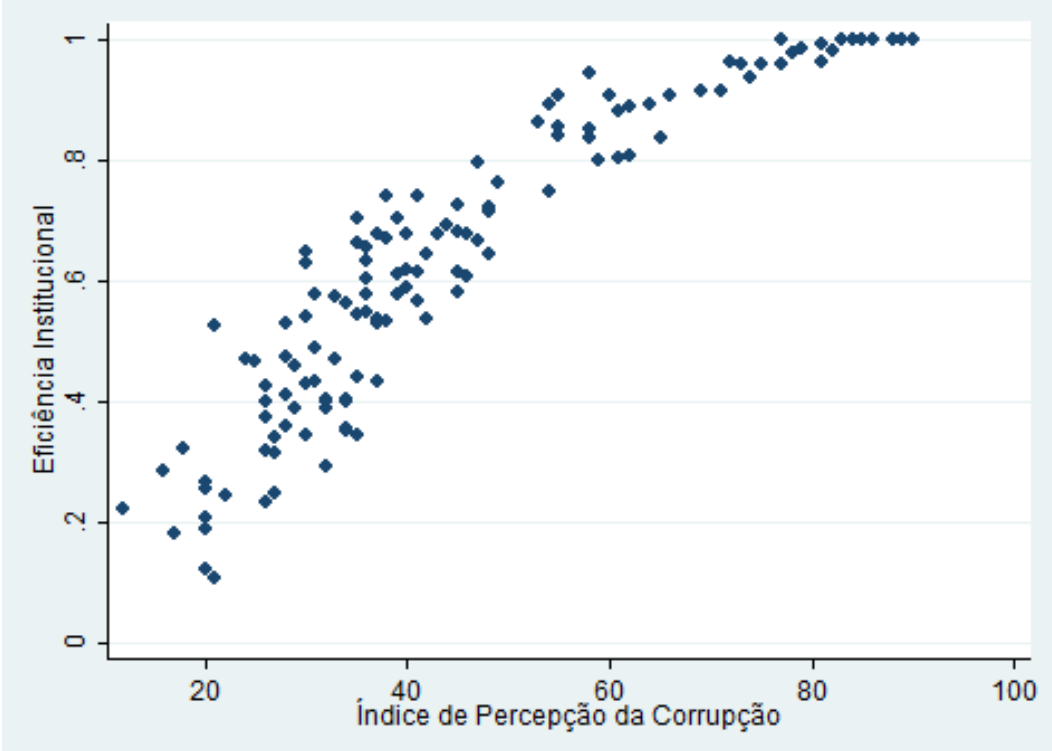

Fonte: Resultados da pesquisa.

Nota: A correlação existente entre as variáveis foi de 0,9161 .

Tabela 3: Estimativas da regressão para os determinantes da eficiência institucional

\begin{tabular}{|c|c|c|c|c|}
\hline Variáveis & $\begin{array}{l}\text { Coeficientes } \\
\text { estimados }\end{array}$ & $\begin{array}{c}\text { Erros } \\
\text { padrões } \\
(\text { bootstrap })\end{array}$ & \multicolumn{2}{|c|}{$\begin{array}{c}\text { Intervalos de } \\
\text { confiança } \\
(95 \%)\end{array}$} \\
\hline Índice de percepção da corrupção & $0,0106^{*}$ & 0,0009 & 0,0087 & 0,0126 \\
\hline Índice de liberdade econômica & $0,0057^{*}$ & 0,0013 & 0,0030 & 0,0083 \\
\hline Índice de liberdade política & $-0,0063$ & 0,0061 & $-0,0188$ & 0,0057 \\
\hline Fragmentação etnolinguística & $-0,0530^{* * *}$ & 0,0291 & $-0,1122$ & 0,0025 \\
\hline Carga tributária & $0,0031^{*}$ & 0,0009 & 0,0012 & 0,0049 \\
\hline Dummy de inclinação ${ }^{+}$ & $-0,0001$ & 0,0006 & $-0,0012$ & 0,0011 \\
\hline _constante & $-0,1869^{* *}$ & 0,0941 & $-0,3665$ & 0,0016 \\
\hline
\end{tabular}

Fonte: Resultados da pesquisa.

Nota: $\left({ }^{*}\right)$ significativo a $1 \% ;\left({ }^{* *}\right)$ significativo a $\left.5 \% ;{ }^{* * *}\right)$ significativo a $10 \% ;(+)$ captura o

efeito de interação entre o nível de desenvolvimento (desenvolvido ou em

desenvolvimento) do país e o índice de percepção da corrupção sobre a eficiência institucional. 
coeficiente estimado mostra que a relação entre liberdade econômica e eficiência institucional é positiva, indicando que quanto mais "livre" o país, mais eficientes são suas instituições. De acordo com Kandil (2009), a liberdade econômica contribui para a estabilidade política e manutenção dos direitos de propriedade. Logo, seu impacto sobre a eficiência institucional é positivo.

Adicionalmente, Adkins et al. (2002) e Dang (2009) encontram relação positiva entre liberdade econômica e eficiência. Embora os autores não mensurem o quanto essa variável afeta a eficiência institucional, eles relacionam positivamente liberdade econômica e instituições.

O índice de liberdade política não apresentou significância estatística. Esse resultado vai de encontro aos resultados obtidos por Javed (2013), que relata relação positiva entre liberdade civil e qualidade institucional. Além disso, Salinas Jiménez \& Salinas Jiménez (2006) destacam que a falta de liberdade civil frequentemente acompanha distorções no mercado, provocando alocação ineficiente dos recursos e, consequentemente, prejudicando a eficiência institucional.

Adicionalmente, Borner et al. (2004) revelam que as instituições tendem a ser mais eficientes em países onde a liberdade civil é maior e os direitos políticos são garantidos, pois os cidadãos podem expressar suas opiniões livremente, sem repressão ou qualquer tipo de censura e isso restringe o comportamento do governo.

Ainda assim, como já mencionado, o efeito do índice de liberdade política sobre a eficiência institucional não foi estatisticamente significativo nesta pesquisa. Uma possível justificativa para esse resultado é a baixa amplitude dessa variável em relação às demais. Como descrito na Tabela 2 , diferentemente do índice de liberdade econômica que varia de 0 a 100, o índice de liberdade política varia de 1 a 7 , amplitude consideravelmente inferior, o que pode interferir no seu efeito sobre a variável dependente, no caso a eficiência institucional.

Já a variável que representa fragmentação etnolinguística obteve, como esperado, relação negativa e estatisticamente significativa. Desse modo, podese dizer que a fragmentação etnolinguística reduz a eficiência das instituições. De acordo com Easterly \& Levine (1997), Alesina et al. (2003) e Easterly et al. (2006), a heterogeneidade pode gerar conflitos e prejudicar a cooperação entre grupos distintos, afetando negativamente as instituições.

Cabe ainda salientar que esse resultado não implica que a fragmentação etnolinguística é um fator negativo. Apenas reflete que em países com maior heterogeneidade são necessários mais esforços para otimização dos recursos. Isso porque, segundo Easterly et al. (2006), é possível que políticos oportunistas explorem essas diferenças com o intuito de acentuar a divisão social e construir sua base de poder, dificultando a formação de instituições eficientes.

A carga tributária foi estatisticamente significativa, demonstrando que seu efeito sobre a eficiência das instituições é positivo. Tal resultado corrobora com aqueles obtidos por Alonso \& Garcimartín (2013), que identificaram relação positiva entre qualidade institucional e carga tributária. Para os autores, quanto maior a receita obtida por meio de tributos, mais próxima e exigente a relação entre cidadãos e Estado, fazendo com que as instituições sejam mais eficientes.

A dummy de inclinação, como já mencionado, revela se o impacto da corrupção sobre a eficiência institucional, considerando se o país é classificado como desenvolvido ou em desenvolvimento, é diferente. Como pode-se observar, essa variável não apresentou significância estatística, ou seja, embora 
a corrupção seja prejudicial para a eficiência das instituições, não se pode afirmar que seu impacto sobre as instituições de países desenvolvidos ou em desenvolvimento ocorra de forma diferente.

Diante dos resultados obtidos, é importante fazer algumas considerações. É de suma importância que os países priorizem políticas de combate à corrupção, haja vista seu efeito significativo e negativo sobre as instituições. Com tais políticas, as instituições podem se tornar mais eficientes, prestando serviços de maior qualidade, com foco no interesse público, criando um ambiente propício para o crescimento e desenvolvimento do país.

Ressalta-se que deixar de combatê-la, segundo Méon \& Weill (2010), poderia haver deterioração das instituições, prejudicando inclusive a produtividade do país. Para os autores, o combate à corrupção deve ser incentivado juntamente com esforços para melhorar o quadro institucional. Nesse ínterim, na Tabela $4^{12}$, pode-se observar os fatores que mais afetam a eficiência institucional e, portanto, devem ser priorizados para elevar a eficiência das instituições.

Tabela 4: Elasticidade dos determinantes da eficiência institucional

\begin{tabular}{l|c|c|c|c}
\hline \multicolumn{1}{c|}{ Variáveis } & Elasticidades & $\begin{array}{c}\text { Erros } \\
\text { padrões } \\
\text { (delta- } \\
\text { method })\end{array}$ & $\begin{array}{c}\text { Intervalos de } \\
\text { confiança (95\%) }\end{array}$ \\
\hline Índice de percepção da corrupção & $0,7266^{*}$ & 0,0674 & 0,5946 & 0,8586 \\
Índice de liberdade econômica & $0,6127^{*}$ & 0,1449 & 0,3287 & 0,8967 \\
Índice de liberdade política & $-0,0487$ & 0,0493 & $-0,1452$ & 0,0479 \\
Fragmentação etnolinguística & $-0,0468^{* * *}$ & 0,0259 & $-0,0975$ & 0,0039 \\
Carga tributária & $0,1182^{*}$ & 0,0341 & 0,0513 & 0,1851 \\
Dummy de inclinação+ & $-0,0015$ & 0,0073 & $-0,0157$ & 0,0127 \\
\hline
\end{tabular}

Fonte: Resultados da pesquisa.

Nota: $\left({ }^{*}\right)$ significativo a $1 \% ;\left({ }^{* *}\right)$ significativo a $5 \% ;\left({ }^{* * *}\right)$ significativo a $10 \%$

É possível verificar que o coeficiente do índice de percepção da corrupção é o de maior magnitude, seguido pelo índice de liberdade econômica, carga tributária e fragmentação etnolinguística. Apenas a fragmentação etnolinguística possui relação inversa com a eficiência institucional, cujo aumento de $10 \%$ equivale à redução média de, aproximadamente, $0,5 \%$ na eficiência. Já o aumento de $10 \%$ no índice de liberdade econômica e na carga tributária implicam em aumento de $6,1 \%$ e 1,2\% na eficiência das instituições, respectivamente. O aumento do IPC em 10\%, isto é, a redução da corrupção em 10\%, eleva, em média, 7,3\% a eficiência das instituições.

Diante de tais resultados, verifica-se a relevância de políticas de combate à corrupção para tornar as instituições mais eficientes. Ainda que outros fatores tenham influência significativa sobre as instituições, o combate à corrupção pode trazer benefícios além dos institucionais.

Segundo Salinas Jiménez \& Salinas Jiménez (2006), a corrupção, por meio do efeito negativo sobre o capital humano, pode afetar significativamente o

\footnotetext{
${ }^{12}$ Apresenta o quanto a variação percentual de cada variável explicativa altera, percentualmente, a variável dependente, ou seja, a eficiência institucional. Em outras palavras, apresenta a variação percentual da eficiência institucional, dada a variação percentual de cada variável explicativa.
} 
progresso tecnológico do país, fator relevante para o processo de crescimento econômico. Além disso, países menos corruptos são mais produtivos (Méon \& Weill 2005), atraem mais investimentos (Mauro 1995) e possuem gestão mais eficiente de recursos direcionados a educação e saúde (Lopes \& Toyoshima 2013). Logo, os benefícios da redução da corrupção ultrapassam os causados às instituições.

Ainda assim, é válido considerar os demais fatores que exercem influência sobre a eficiência institucional ao adotar medidas que visem aumentar essa eficiência. Ou seja, para que as políticas e estratégias adotadas sejam eficazes, é necessário que tais fatores sejam avaliados. É importante ressaltar que essas políticas podem trazer impactos ainda mais significativos no longo prazo, haja vista a importância das instituições para o crescimento econômico.

Adicionalmente, é preciso considerar a possibilidade de efeitos distintos da corrupção sobre a eficiência das instituições. Alguns estudos (Aidt et al. 2008, Méon \& Weill 2010, De Vaal \& Ebben 2011, Gottschild 2016) revelam que a corrupção pode não ser prejudicial ou até trazer benefícios em países cujas instituições são frágeis. Diante disso, a Figura 3 apresenta as médias das elasticidades do IPC para diferentes níveis de corrupção.

Figura 3: Elasticidades médias do Índice de Percepção da Corrupção (IPC) com intervalos de confiança de 95\%

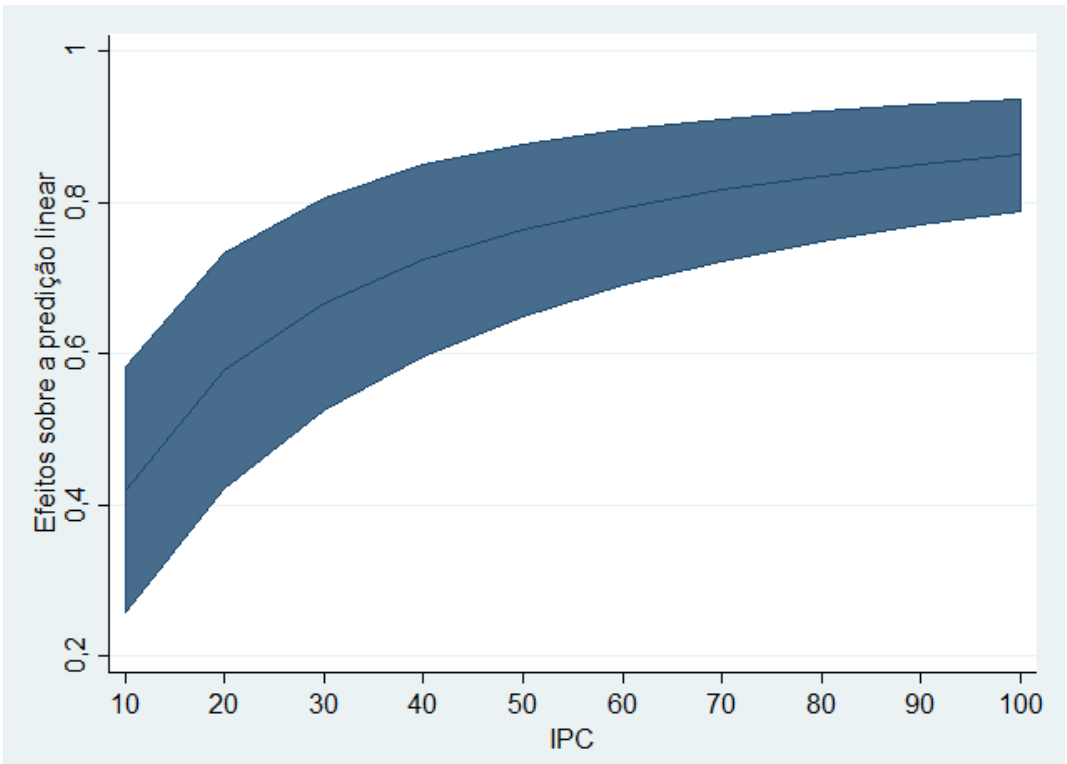

Fonte: Resultados da pesquisa.

É possível observar que nos países mais corruptos (menores IPC's), o efeito marginal da corrupção sobre a eficiência institucional é menor. Pressupondose que nos países onde a corrupção é mais elevada, as instituições são menos eficientes, pode-se concluir que tal resultado corrobora com aquele encontrado por Méon \& Weill (2010), que revelou menor impacto da corrupção sobre a eficiência em países com um quadro institucional deficiente.

Adicionalmente, o estudo realizado por Aidt et al. (2008) identifica efeito negativo da corrupção em regimes com instituições políticas de elevada quali- 
dade, porém, o mesmo não ocorre em países com instituições deficientes. Segundo Aidt et al. (2008) e Méon \& Weill (2010), nesses países, as instituições são tão frágeis e ineficientes que a corrupção acaba não tendo efeito significativo sobre elas. Os autores ainda relacionam esse resultado com a hipótese "grease the wheels", em que nos países com instituições falhas, a corrupção pode melhorar a eficiência ao permitir que os indivíduos contornem deficiências institucionais existentes.

Embora Aidt et al. (2008) e Méon \& Weill (2010) tenham encontrado resultados que indiquem a possibilidade da corrupção não trazer prejuízos, eles destacam que nesse caso seria necessária uma análise mais ampla. Isso porque a referida análise está relacionada com fatores específicos, como produtividade e eficiência agregada, e conforme literatura existente, sabe-se que a corrupção deteriora outros fatores, como investimentos, acumulação de capital e rendimentos.

O presente estudo revela que mesmo nos países mais corruptos, que possivelmente possuem instituições menos eficientes, a corrupção exerce efeito negativo, ainda que em menores proporções. Portanto, políticas e estratégias de combate à corrupção são de suma importância e, se forem bem sucedidas, as instituições se tornarão mais eficientes, criando ambiente propício para o desenvolvimento econômico dos países.

Nesse sentido, os governos que objetivam elevar o nível de desenvolvimento econômico devem priorizar políticas de combate à corrupção. Como apresentado no presente trabalho, o comportamento corrupto do agente torna as instituições ineficientes, prejudicando os serviços por elas oferecidos. Conforme a Teoria da Agência, esse comportamento oportunista é proveniente das informações privilegiadas que o agente possui em relação ao principal (assimetria de informações). Diante disso, uma das formas para combater a corrupção seria criar estratégias que ampliem a disponibilidade de informações para toda população (burocratas, governo e cidadãos). Conforme apresentado por Araújo \& Sanchez (2005), a tecnologia de informação e comunicação (TIC) pode ser uma ferramenta eficaz para alcançar esse objetivo, haja vista sua capacidade de captar e concentrar informações, favorecendo a formação de arranjos institucionais que limitem o comportamento oportunista dos agentes públicos.

Por fim, é importante destacar o papel da população nesse contexto. Considerando-se que os políticos devem prestar contas aos cidadãos, esses devem exercer seu poder de voto e reivindicar a criação de políticas e estratégias que visem a obtenção e disseminação de informações, de tal forma que a assimetria de informações seja minimizada e o comportamento corrupto seja limitado.

Tendo em vista que as instituições são fundamentais para a prestação de serviços à população e que a corrupção as torna ineficientes, ao combatê-la, os serviços prestados serão de maior qualidade, proporcionando maior bemestar à população. Além disso, as instituições são essenciais para promoção do desenvolvimento econômico. Portanto, políticas de combate à corrupção são necessárias. A inexistência de tais políticas pode levar o país a um círculo vicioso em que as instituições se tornam cada vez mais ineficientes, impedindo o processo de desenvolvimento. 


\section{Considerações Finais}

A corrupção tem sido um problema enfrentado por diversos países ao redor do mundo. Seus prejuízos são inúmeros, afetando inclusive o ambiente institucional do país. Considerando que uma estrutura institucional sólida e eficiente é essencial para o crescimento e desenvolvimento de uma nação, o impacto da corrupção nas instituições pode afetar seu desempenho econômico.

Nesse contexto, a presente pesquisa teve como objetivo identificar o efeito da corrupção na eficiência institucional dos países. Acredita-se que a corrupção pode tornar as instituições menos eficientes a partir do momento que interfere na atuação dos burocratas, que passam a priorizar interesses próprios em detrimento do interesse público.

Inicialmente, calculou-se o índice de eficiência institucional dos países por meio da análise envoltória de dados. Os resultados revelam que Dinamarca, Finlândia, Nova Zelândia, Noruega, Países Baixos, Singapura, Suécia e Suíça possuem instituições relativamente eficientes.

Constatou-se também que a média da eficiência institucional foi de 0,625 e o continente europeu obteve a maior média $(0,886)$. Já as médias obtidas pelos continentes latino-americano e africano foram inferiores à média da amostra, com destaque para a África, que apresentou média consideravelmente inferior: 0,440. Esses resultados indicam a necessidade do direcionamento de esforços para melhorar a qualidade institucional dos países.

Posteriormente, por meio de um modelo econométrico, verificou-se que a corrupção tem impacto negativo e significativo sobre a eficiência institucional. A redução de $10 \%$ na corrupção aumenta, em média, mais de $7 \%$ a eficiência das instituições. Além disso, o IPC foi a variável que apresentou maior impacto na eficiência institucional, evidenciando a importância de políticas públicas que visem combater a corrupção.

Essas políticas se tornam ainda mais relevantes ao considerar os diversos prejuízos causados pela corrupção à sociedade. A inexistência de tais políticas pode impedir que as instituições deixem de ser ineficientes, impedindo que os países tenham melhor desempenho econômico. Logo, o combate à corrupção deve ser uma das prioridades dos governantes.

O presente estudo ainda demonstra que o efeito marginal da corrupção sobre a eficiência institucional é heterogêneo. Ainda que seu efeito sobre as instituições seja negativo, o mesmo é mais elevado em países menos corruptos. Assim, ressalta-se a importância de políticas de combate à corrupção em todos os países, independentemente do seu nível de corrupção, dados os danos causados por ela.

De maneira geral, o presente estudo fornece informações úteis para os formuladores de políticas públicas, revelando a importância do combate à corrupção para promover a eficiência institucional e, consequentemente, a prosperidade econômica dos países. Adicionalmente, demonstra a necessidade de se considerar outros fatores que exercem influência sobre o ambiente institucional para que as referidas políticas sejam formuladas e implementadas de forma eficaz.

\section{Referências Bibliográficas}

Acemoglu, D. \& Robinson, J. (2012). Why nations fail: the origins of power, prosperity and poverty. New York: Crown Publishers. 
Adkins, C., Moomaw, R. \& Savvides, A. (2002). Institutions, freedom, and technical efficiency. Southern Economic Journal, v. 69, n. 1, p. 92-108.

Aidt, T. (2003). Economic analysis of corruption: a survey. Economic journal, v. 113, n. 491, p. F632-F652.

Aidt, T., Dutta, J. \& Sena, V. (2008). Governance regimes, corruption and growth: theory and evidence. Journal of Comparative Economics, v. 36, n. 2, p. 195-220, mês ano. DOI: DOI: 10.1016/j.jce.2007.11.004.

Alesina, A., Devleeschauwer, A., Easterly, W. \& Kurlat, S. (2003). Fractionalization. Journal of Economic Growth, v. 9, n. 2, p. 155-94.

Alonso, J. A. \& Garcimartín, C. (2013). The determinants of institutional quality. More on the debate. Journal of International Development, v. 25, n. 2, p. 206-226. DOI: 10.1002/jid.1710.

Araújo, M. \& Sanchez, O. A. (2005). A corrupção e os controles internos do Estado. Lua Nova, v. 65, p. 137-173.

Ayub, M. (2015). Análise econômica das instituições anticorrupção no Brasil. Disponível em: http://www3.pucrs.br/pucrs/files/uni/poa/direito/graduacao/tcc/tcc2/tra balhos2015_2/marcelo_monteiro.pdf. Acesso em: 16 de março de 2018.

Banker, R. D., Charnes, H. \& Cooper, W. W. (1984). Some models for estimating technical and scale inefficiencies in data envelopment analysis. Management Science, v. 30, n. 9, p. 1078-1092. DOI: 10.1287/mnsc.30.9.1078.

Borner, S., Bodmer, F. \& Kobler, M. (2004). Institutional efficiency and its determinants: the role of political factors in economic growth. Paris: OECD Development Centre.

Bueno, N. P. (2009). Corrupção: teoria, evidências empíricas e sugestões de medidas para reduzir seus níveis no Brasil - uma análise institucional. Revista da CGU, n. 6, p. 71-84, set.

Carraro, A. \& Hillbrecht, R. O. (2003). Modelos Microeconômicos de Corrupção Burocrática e Seus Determinantes Econômicos. Disponível em: http://www.anpec.org.br/encontro2003/artigos/D36.pdf . Acesso em: 15 maio de 2018.

Charnes, A., Cooper, W. W. \& Rhodes, E. (1978). Measuring the efficiency of decision making units. European Journal of Operational Research, v. 2, n. 6, p. 429-444. DOI: 10.1016/0377-2217.

Coelli, T., Rao, D. S. P. \& Battese, G. E. (1998). An introduction to efficiency and productivity analysis. Norwell: Kluwer Academic.

Cooper, W. W., Seiford, L. M. \& Tone, K. (2007). Data envelopment analysis: a comprehensive text with models, applications, references and DEA-solver software. New York: Springer.

Dang, V. (2009). Institutions and efficiency in transition economies. Economics and Finance Working Paper Series. Working paper nr. 09-32, ago. 
De Vaal, A. \& Ebben, W. (2011). Institutions and the relation between corruption and economic growth. Review of Development Economics, v. 15, n. 1, p. 108-123. DOI: 10.1111/j.1467-9361.2010.00596.x.

Easterly, W., J, R. \& Woolcock, M. (2006). Social Cohesion, Institutions, and Growth.. Center for Global Development, Working Paper 94.

Easterly, W. \& Levine, R. (1997). Africa's Growth Tragedy: Policies and Ethnic Divisions. Quarterly Journal of Economics, v. 112, n. 4, p. 1203-50.

Freedom House (2016). Freedom in the world 2016, table of country scores. Disponível em: https://freedomhouse.org/report/freedom-world-2016/tablescores. Acesso em: 10 de outubro de 2018.

Furlanetto, E. L. (2008). Instituições e desenvolvimento econômico: a importância do capital social. Rev. Sociol. Polit., Curitiba, v. 16, nr. sup., p. 55-67, ago.

Gottschild, P. H. (2016), PhD thesis. A relação entre corrupção e desenvolvimento econômico: a contribuição da economia. 31f. Monografia. (Bacharel em Ciências Econômicas) - Setor de Ciências Sociais Aplicadas, Universidade Federal do Paraná, Curitiba.

Hayashi, F. E. H. (2012). O impacto da corrupção sobre o desenvolvimento dos países. Disponível em: http://www.publicadireito.com.br/artigos/?cod=d8ab1a52f058358b.

Acesso em: 15 de maio de 2018.

International Monetary Fund - IMF (2017). World Economic Outlook: seeking sustainable growth - shortterm recovery, long-term challenges. Disponível em: https://www.imf.org/en/Publications/WEO/Issues/2017/09/19/worldeconomic-outlook-october-2017. Acesso em: 15 de junho de 2018.

Javed, O. (2013). Determinants of institutional quality: a case study of IMF programme countries. MPRA Paper, University of Barcelona, Spain.

Kandil, M. (2009). Determinants of institutional quality and their impact on economic growth in the MENA region. International Journal of Development Issues, v. 8, n. 2, p. 134-167.

Lambsdorff, J. G. (2003). How corruption affects productivity. KYKLOS, v. 56, n. 4, p. 457-474.

Leff, N. (1964). Economic development through bureaucratic corruption. American behavioral scientist, v. 8, n. 3, p. 8-14.

Lopes, L. S. \& Toyoshima, S. H. (2013). Evidências do impacto da corrupção sobre a eficiência das políticas de saúde e educação nos estados brasileiros. Planejamento e Políticas Públicas, n. 41, jul./dez.

Lui, F. (1985). An equilibrium queuing model of bribery. Journal of political economy, v. 93, n. 4, p. 760-781.

Mauro, P. (1995). Corruption and growth. Quarterly journal of economics, v. 110 , n. 3, p. 681-712. 
Melo, M. (1996). Governance e reforma do Estado. O paradigma agente $\mathrm{x}$ principal. Revista do Serviço Público, v. 120.

Méon, P. \& Weill, L. (2005). Does better governance foster efficiency? An aggregate frontier analysis. Economics of Governance, v. 6, n. 1, p. 75-90.

Méon, P. \& Weill, L. (2010). Is corruption an efficient grease? World development, v. 38, n. 3, p. 244-259.

North, D. C. (2006). Custos de Transação, Instituições e Desempenho Econômico. São Paulo: Instituto Liberal.

Olken, B. A. (2009). Corruption perceptions vs. Corruption reality. Journal of Public Economics, v. 93, n. 7, p. 950-964.

Ortiz-Ospina, E. \& Roser, M. (2016). Corruption. Our world in data. Disponível em: https://ourworldindata.org/corruption. Acesso em: 30 de julho de 2020 .

Programa das Nações Unidas - PNUD (2018). Human development reports. Disponível em: http://hdr.undp.org/en/data . Acesso em: 10 de setembro de 2018.

Romer, P. (1994). New goods, old theory, and the welfare costs of trade restrictions. Journal of Development Economics, v. 43, p. 5-38.

Sachsida, A. (2011). Qualidade das instituições e crescimento econômico. Boletim regional, urbano e ambiental, IPEA, n. 05, jun.

Salinas Jiménez, M. \& Salinas Jiménez, J. (2006). Corruption and productivity growth in OECD countries. Disponivel em: http://wwwsre.wu.ac.at/ersa/ersaconfs/ersa06/papers/99.pdf. Acesso em: 14 de março de 2018.

Schillemans, T. (2013). Moving beyond the clash of interests on stewardship theory and the relation-ships between central government departments and public agencies. Public Management Review, v. 15, n. 4, p. 541-562.

Simar, L. \& Wilson, P. W. (1998). Sensitivity analysis of efficiency scores: how to bootstrap in nonparametric frontier models. Manage Sci. v. 44, n. 1, p. 49-61.

Simar, L. \& Wilson, P. W. (2007). Estimation and inference in two-stage, semiparametric models of production processes. Journal of Econometrics, v. 136, n. 1, p. 31-64.

Svensson, J. (2005). Eight questions about corruption. Journal of economic perspectives, v. 19, n. 3 , p. 19-42.

Tanzi, V. (1998). Corruption around the world: causes, consequences, scopes and cures. IMF Staff Papers, v. 45, n. 4, p. 559-594.

Tanzi, V. \& Davoodi, H. (1997). orruption, public investment, and growth. IMF Working Paper, nr. 97-139. 
The Heritage Foundation (2016). Index of economic freedom. Disponível em: https://www.heritage.org/index/explore?viewb̄y-region-countryyear\&ū̄ 36867881175428662. Acesso em: 10 de março de 2018.

Transparência Internacional (2016). Corruption Perceptions Index. Disponível em: https://www.transparency.org/news/feature/corruption_perceptions_ index_2016. Acesso em: 10 de outubro de 2018.

Transparência Internacional (2017). Corruption Perceptions Index. Disponível em: https://www.transparency.org/news/feature/corruption_perceptions_ index_2017. Acesso em: 10 de junho de 2018.

Votápková, J. \& Zác, M. (2013). Institutional efficiency of selected EU \& OECD countries using DEA-LIKE approach. Prague Economic Papers, v. 2. DOI: $10.18267 /$ j.pep. 448 .

Worldwide Governance Indicators - WGI (2017). Disponível em: http://info.worldbank.org/governance/wgi/\#home . Acesso em: $14 \mathrm{de}$ março de 2018.

\section{Apêndice A}

Figura A.1: Relação entre o Índice de Percepção de Corrupção (IPC) e a proporção de pessoas que subornaram

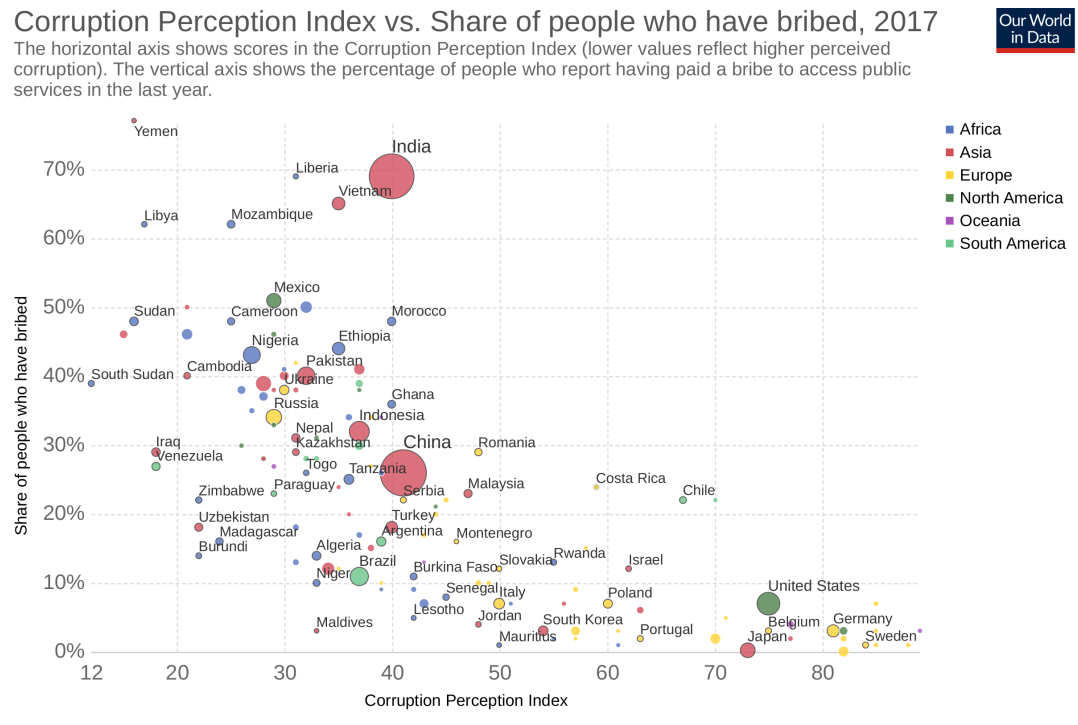

Source: Transparency International (2018), Transparency International - GCB (2017)

Fonte: Ortiz-Ospina \& Roser (2016). 
Tabela A.1: Relação dos países de acordo com o nível de eficiência institucional

\begin{tabular}{|c|c|}
\hline $\begin{array}{l}\text { Níveis de eficiência } \\
\text { institucional }\end{array}$ & Países \\
\hline $\begin{array}{l}\text { Até } \\
0,527\end{array}$ & $\begin{array}{l}\text { África Central, Angola, Argélia, Bolívia, Burundi, Cama- } \\
\text { rões, Camboja, Chade, Comores, Congo, Costa do Mar- } \\
\text { fim, Egito, Equador, Etiópia, Gabão, Gâmbia, Guatemala, } \\
\text { Guiné, Guiné-Bissau, Haiti, Honduras, Irãa, Líbano, Libéria, } \\
\text { Madagascar, Malaui, Mali, Mauritânia, Moçambique, Ne- } \\
\text { pal, Nicarágua, Níger, Nigéria, Papua Nova Guiné, Paquis- } \\
\text { tão, Quênia, República Democrática do Congo, Serra Leoa, } \\
\text { Tanzânia, Togo, Uganda, Venezuela, Zimbábue. }\end{array}$ \\
\hline $\begin{array}{c}\mathrm{De} \\
0,527 \text { a } 0,739\end{array}$ & $\begin{array}{l}\text { África do Sul, Albânia, Arábia Saudita, Argentina, Benin, } \\
\text { Brasil, Burkina Faso, China, Colômbia, Cuba, El Salvador, } \\
\text { Filipinas, Gana, Guiana, Grécia, Hungria, Ilhas Salomão, } \\
\text { Índia, Indonésia, Jamaica, Jordânia, Laos, Lesoto, Maldi- } \\
\text { vas, Marrocos, México, Mongólia, Omã, Panamá, Paraguai, } \\
\text { Peru, República Dominicana, São Tomé e Príncipe, Sene- } \\
\text { gal, Romênia, Sri Lanka, Suriname, Tailândia, Trinidade e } \\
\text { Tobago, Tunísia, Turquia, Vietnã, Zâmbia. }\end{array}$ \\
\hline $\begin{array}{c}\text { Acima de } \\
0,739\end{array}$ & $\begin{array}{l}\text { Austrália, Áustria, Barbados, Bélgica, Butão, Botswana, } \\
\text { Brunei, Bulgária, Cabo Verde, Canadá, Chile, Chipre, Co- } \\
\text { reia do Sul, Costa Rica, Dinamarca, Espanha, Estados Uni- } \\
\text { dos, Finlândia, França, Grécia, Hong Kong, Irlanda, Islân- } \\
\text { dia, Israel, Itália, Japão, Luxemburgo, Malásia, Malta, Mau- } \\
\text { rícia, Mongólia, Noruega, Nova Zelândia, Países Baixos, } \\
\text { Polônia, Portugal, Qatar, Reino Unido, República Tcheca, } \\
\text { Ruanda, Singapura, Suécia, Suíça, Uruguai. }\end{array}$ \\
\hline
\end{tabular}

Fonte: Resultados da pesquisa. 